\title{
EDUCAÇÃO INTEGRAL: REFLEXÕES HISTÓRICAS SOBRE SEU PROCESSO DE IMPLANTAÇÃO
}

Jacqueline Araújo Pereira, Larissa Alves Matias, Nair Correia Salgado de Azevedo.

Universidade do Oeste Paulista - UNOESTE, Presidente Prudente, SP. E_mail: jacquelineap @hotmail.com, larissamatias22@hotmail.com, nairazevedo@hotmail.com.

\section{RESUMO}

Esse estudo, de caráter bibliográfico, pretende discutir quais as concepções de Educação Integral perduraram em determinados contextos históricos da educação no Brasil, mais precisamente nas décadas de 1930, 1980 e nos dias atuais. Pretende-se refletir sobre o processo histórico de implantação das políticas de ampliação do tempo escolar assim como a visão predominante hoje da Educação Integral: a visão assistencialista. Ampliar o tempo sem mudar concepções pedagógicas podem ocasionar alguns equívocos, como o oferecimento do que já existe, da mesma forma, em horário ampliado. Sendo assim, corre-se o risco de oferecer uma educação que não contemple os saberes diversos como proposta educativa, o que caracteriza um dos objetivos da Educação Integral. Esse estudo também discutirá a visão assistencialista nesse tipo de ensino, além de refletir sobre como a Educação Integral tem sido realizada visando o processo de ampliação do tempo comparando com as necessidades reais das crianças, para que essas usufruam de uma Educação Integral plena.

Palavras-chave: Educação Integral. Ampliação do tempo. Assistencialismo. História da Educação.

\section{INTEGRAL EDUCATION : HISTORICAL REFLECTIONS ON HISTORICAL ITS RULES OF DEPLOYMENT}

\begin{abstract}
This study, bibliographic character, which discusses the concepts of Integral Education persisted in certain historical contexts of education in Brazil, more precisely in the 1930s, 1980s and today. It is intended to reflect on the historical process of implementation of the expansion of school time policy as well as the prevailing view today's Integral Education: the paternalistic vision. Extend the time without changing pedagogical concepts can lead to some misconceptions, such as the offering of what already exists in the same way, in extended hours. Thus, there is the risk of offering an education that does not address the diverse knowledge and educational proposal, which features one of the goals of Integral Education. This study will also discuss the paternalist view this type of education, and reflect on how the Integral Education has been carried out for the time expansion process school compared to the real needs of children, for these to lead a full Integral Education.
\end{abstract}

Keywords: Integral Education. Extension school time. Welfarism. History of Education.

\section{INTRODUÇÃO}

Durante a história da Educação do Brasil foram muitas as tentativas e estratégias realizadas para que se pudesse melhorar a qualidade do ensino. A utilização de muitos métodos variados, as mudanças de concepções pedagógicas que pudessem viabilizar o sucesso escolar, entre outros, foram adotados em alguns momentos. Entretanto, outra estratégia esteve diretamente ligada a tais tentativas de melhora da qualidade da educação, em diversos momentos: a ampliação do tempo escolar seja através do aumento de horas diárias ou pelo aumento de anos durante determinado ciclo educacional.

Tais propostas de ampliação do tempo escolar, embora com intenções diretas de auxiliar e promover uma educação que ampliasse os conhecimentos dos alunos muitas vezes caiu em algumas ciladas, pois ampliar o tempo sem mudar concepções pedagógicas, traz o risco de oferecer um ensino com "mais do mesmo", e nesse caso cabe uma reflexão: é possível melhorar a qualidade da educação oferecendo 
em dobro o que já existe nas escolas e da mesma maneira?

Em se tratando de escola pública, o ensino sempre se propôs a oferecer à população mais carente o mínimo. Isso se traduz nas palavras de Cavaliere (2009) em um ensino com poucas horas diárias, com poucos recursos materiais e com poucos profissionais, ou seja, com o mínimo de investimento possível.

A Educação Integral é uma proposta voltada para diminuir as diferenças sociais e de ensino, porém cada experiência precisa ser analisada em sua dimensão concreta para que possamos emitir juízos parciais sobre tal. No caso da sociedade brasileira, a Educação Integral foi associada em muitos momentos a concepções assistencialistas, e não a concepções que promovem o desenvolvimento global do aluno de forma a contemplar vários saberes (CAVALIERE, 2009).

Assim, esse estudo pretende discutir quais as concepções de Educação Integral prevaleceram durante alguns momentos históricos da educação no Brasil, como por exemplo, em seu início, na década de 1930 e idealizada por Anísio Teixeira, além da década de 1980 que teve na experiência carioca com a criação do "Centro Integrado de Educação Pública", os CIEPs, uma tentativa de volta às origens, trazendo a seguinte reflexão para os dias atuais: hoje, qual o verdadeiro sentido de se realizar uma Educação Integral?

Conforme Azevedo (2012), a formação do ser humano nos aspectos educacionais deve englobar o estímulo ao desenvolvimento humano em sua totalidade e um dos espaços que oferecem estes princípios são as escolas. $\mathrm{Na}$ Educação Integral percebe-se que a formação vai além do aumento das horas gastas na escola e da mesma forma, as instituições que possuem seu horário de forma integral devem contar com estrutura adequada, além de profissionais com formação capaz de atender as demandas educacionais.

A escola de Educação Integral até consegue atingir níveis de satisfação nos aspectos relativos à formação, todavia é preciso se ater às individualidades dos alunos, respeitando seus saberes e estimulando suas competências. Além disso, não podemos nos esquecer do fator tempo, pois toda escola que opta pela Educação Integral precisa ter sua rotina ajustada de forma a incitar o desenvolvimento do ser humano enquanto cidadão. Portanto, é necessário também conhecer a realidade social à qual a escola de Educação Integral foi pensada, para que este ou qualquer outro programa educacional consiga atender efetivamente as necessidades educacionais dos educandos.

\section{PERCURSO HISTÓRICO DA EDUCAÇÃO INTEGRAL}

A idealização e construção da Educação Integral se inserem na criação da educação brasileira, haja vista que muitos movimentos foram realizados ao longo da história. Para Cavaliere (2002b), essa intenção de melhorar a escola vem desde os primórdios em que o Brasil passou a ser uma república e, assim, algumas leis foram criadas com o intuito de tornar os desenvolvimentos históricos e humanos da sociedade mais robustos.

Com o passar do tempo, mais precisamente no início do século $\mathrm{XX}$, alguns movimentos, como os sindicais, por exemplo, foram ganhando mais força e educar se tornou uma das metas principais dos governantes, sendo esta voltada para formação de mão de obra para a indústria ou mesmo para desenvolver o ser humano (KASSICK, 2008). Vemos também em Libâneo (2012) que o condicionamento da realidade educacional e a estrutura política do país sempre tiveram a escola como uma de suas integrantes, entendendo-a como um norteador para que algumas políticas educacionais pudessem ser implantadas.

Segundo Cavaliere

(2002b), independentemente da época, o que se tentou fazer foi criar uma educação que fosse compatível com os brasileiros levando em conta principalmente questões políticas e sociais que interessavam diretamente os governantes. $\mathrm{Na}$ mesma direção, Coelho (2009) nos alerta que esse interesse do governo teve seu ápice na idealização do modelo educacional escolhido e excepcionalmente em suas diretrizes e princípios.

Por volta das décadas de 1980 e 1990, a educação básica foi fundamentada em parâmetros curriculares nacionais que até hoje são divulgados e seguidos por dirigentes de entidades educacionais (CAVALIERE, 2002b). Nessa mesma época, também segundo Cella (2010), um modelo denominado "Educação Integral" foi amplamente divulgado com intuito de não só ofertar a formação educacional, mas também a humana nas escolas de todo país.

De acordo com Cavaliere (2002b), a ideia da Educação Integral nasceu na década de 1930 
com base fundamentada em posicionamentos político-filosóficos de uma formação humana integral, os quais eram difundidos em debates realizados pelo governo federal, que ouviu, sobretudo, católicos, anarquistas, integralistas e educadores de renome como, por exemplo, Anísio Teixeira. Dessa forma, surgiu uma nova ideia de educação que tentou especialmente formar o ser humano no decorrer de sua época escolar.

Com o passar do tempo, segundo Maurício (2006) os debates acerca da educação foram se tornando mais acalorados e efetivos, 0 que resultou na criação de propostas educacionais. Outro fato positivo indica que os educadores foram solidificando suas respectivas ideias e consequentemente houve a implantação de algumas destas propostas nas escolas, isso graças a essas pessoas que tinham a intenção de tornar as escolas um espaço de formação (CAVALIERE, 2002a).

\subsection{Anísio Teixeira e as "Escolas Parque"}

Dentre os educadores mais importantes do Brasil quando falamos de Educação Integral, segundo Cavaliere (2010), está Anísio Teixeira, um profundo colaborador das mudanças efetuadas no âmbito educacional. Nesta direção, um dos principais fatos realizados pelo mesmo foi a elaboração de uma proposta para a educação escolar que tinha como linha específica alfabetizar de forma ampla a população, bem como o fim dos questionamentos acerca da qualidade da educação popular.

A ideia deste educador, segundo Oliveira (1991), era também criar uma educação na qual houvesse uma ampliação de abrangência dos aspectos sociais e culturais do país. Um contraponto a esta proposta foram os grupos autoritários e elitistas que pensavam que uma escola devia oferecer atividades que pudessem controlar socialmente os alunos, deixando-os reféns e incluídos na separação de classes, ou seja, os dominados (alunos) e os dominadores (grupos hierárquicos e elitistas) separados (PARO, 1988; MAURÍCIO, 2004).

O momento, conforme Cella (2010), era propriamente de renovação. Assim, algumas linhas seguiam os pensamentos de Dewey e fortificaram filosoficamente suas ideias. Esse lastro adotado se enveredou pelo americanismo e a educação passou a ter como princípios uma formação ampliada, tornando o que Kassinck
(2008) explica como um processo contínuo realizado diariamente na educação escolarizada.

Anísio Teixeira tinha em mente que era preciso formar os cidadãos por meio do aprendizado da leitura e da escrita e de atividades que ultrapassavam a alfabetização como, por exemplo, noções de política e ações sociais, pois só assim teríamos uma formação integral. Segundo Cavaliere (2002), nesta época, muitas reformas foram realizadas e numa delas o tempo que o aluno ficava na escola foi reduzido pela metade, fato que gerou alguma polêmica entre os educadores daquele momento. Outra dizia respeito à finalidade social da escola primária, o que segundo Paro (1988) e Maurício (2004), além de formar devia influenciar o meio social.

Já na década de 1980, de acordo com Cella (2010), a proposta era expandir o número de vagas nas escolas, mas outras frentes educacionais advogavam acerca de novamente ampliar o tempo de escolarização primária e a jornada diária escolar, pois os princípios norteadores, nesse caso, visavam muito mais propiciar um local para que as crianças mais desfavorecidas pudessem ficar enquanto seus pais trabalhavam, do que propor um ensino público de qualidade (CELLA, 2010).

Todavia, apesar dos debates atuais, precisamos lembrar que desde a década de 1930 houve a criação de escolas consideradas modelos como, por exemplo, os prédios conjugados que detinham os nomes de "escolas-parque" em que os alunos deviam obrigatoriamente frequentar os dois tipos de ensino. (KERSTENETZKY, 2006; CAVALIERE, 2010).

Segundo Azevedo (2012), as "escolasparques" foram idealizadas por Anísio Teixeira, na década de 1930, voltadas para propor uma Educação Integral às camadas populares nos mesmos moldes da classe média, ou seja, seriam oferecidas atividades nas quais os mais humildes não teriam acesso devido à falta de condições financeiras para tal, como aulas de inglês e de esportes, por exemplo.

$\mathrm{Na}$ mesma linha, o "Centro Educacional Carneiro Ribeiro", outra escola que funcionava na mesma proposta das "escolas-parque" no município de Salvador/BA em meados da década de 1950, serviu como modelo de escola integral sendo que na mesma havia atividades escolares, artísticas, recreativas e educação física. Com uma grande capacidade, muitos alunos eram atendidos numa faixa etária entre sete e 15 anos 
e seu funcionamento era das $07 \mathrm{~h} 30 \mathrm{~min}$ às 16h30min (MAURÍCIO, 2006).

Consequentemente, a ideia de uma Educação Integral formulada por Anísio Teixeira e propostas embasadas nas escolas-parque, serviram de base para que a atual Lei de Diretrizes e Bases da Educação Nacional - LDBEN, no 9.394/96 sugerisse a implantação da Educação Integral nas escolas públicas brasileiras, embora essa não determinasse um prazo que tal implantação ocorra.

\subsection{O emudecimento da Educação Integral: a ruptura através do Regime Militar no Brasil}

De acordo com Paro (1988), tudo que é novidade tende a enfrentar resistência e com a Educação Integral não foi diferente, pois o regime militar, a partir da década de 1960, passou a colocar resistências contra este tipo de escola. As imposições e restrições emitidas pelo governo dificultavam seu desenvolvimento e com o passar do tempo educar se tornou uma ação cada vez mais onerosa por parte dos educadores e, consequentemente, também das escolas.

Numa época histórica em que o governo de característica militar impunha às escolas o que devia ser ensinado, a preocupação era oferecer atividades focadas no patriotismo e que também não deixasse as pessoas irem contra o militarismo autoritário (MAURíCIO, 2004). Eram expressamente proibidas manifestações opostas às ideias do governo e quem pensasse o contrário sofreria com as punições.

Especificamente, o ideal para o militarismo era formar cidadãos sem consciência crítica da verdade que acreditariam voluntariamente e/ou forçadamente nas palavras apregoadas pelos governistas (CAVALIERE, 2002b; KASSICK, 2008). Sendo assim, a restrição à cultura e à consciência social foram soluções impostas para que as pessoas se calassem diante da imposição de regras estabelecidas sem democracia.

Conforme Cavaliere (2002b), nesse momento tudo o que tinha aspecto voltado ao social foi barrado e a educação foi a área mais prejudicada, fato que atingia diretamente os alunos. Como não era permitido expressar suas ideias, muitos educadores contrários à ideologia militar foram obrigados a se calarem ou seriam punidos de forma rigorosa.

Devido a essa turbulência governista a ideia da Educação Integral, segundo Cella (2010), foi muitas vezes ignorada e barrada, pois para o militarismo a liberdade no âmbito escolar não era algo que fazia parte dos seus planos. Oferecer uma conscientização social aliada a uma ampla formação dos alunos era considerado um "crime" contra a administração pública, já que tudo devia ser controlado pelo governo.

0 que ficou claro, conforme interpretações de Paro (1988) e Libâneo (2012) eram que a educação da época não tinha nenhuma intenção de ser democrática, tampouco de proporcionar uma formação integral para os alunos. Tornou-se evidente também que o passar dos anos poderia ser o melhor e mais eficaz remédio para as premissas educacionais, isso foi possível apenas durante o fim do regime militar no governo brasileiro.

\subsection{Darci Ribeiro e os Cieps: $O$ retorno da educação integral a partir da década de $\mathbf{1 9 8 0}$}

O fim do militarismo em meados da década de 1980 trouxe benefícios não só para a população brasileira, mas da mesma maneira para a educação, tendo em vista que a liberdade de expressão e ensino nas escolas passou a ser mais expressiva, conforme Cavaliere (2002b) e Maurício (2004). Com a liberdade nas mãos, a criação de propostas curriculares e de modelos de escola se tornou possível e assim os educadores da época puderam expor suas ideias no âmbito educacional.

Um dos benefícios observados neste momento foi a volta da Educação Integral, o que de acordo com Oliveira (1991) voltou a ser oferecida em algumas cidades de determinados estados brasileiros já no final de década de 1980. O Rio de Janeiro foi um dos primeiros estados a se articular nesse sentido e uma das primeiras ações foi a implantação do "Centro Integrado de Educação Pública" - CIEP, uma medida que contou com a participação dos educadores atuantes no governo (CAVALIERE, 2010).

A proposta de criação dos CIEPs no Rio de Janeiro foi redigida pelo educador Darci Ribeiro, o qual via que o trabalho pedagógico escolar devia conter em suas premissas a Educação Integral. Nesse tempo, foram construídos muitos prédios escolares no estado do Rio que tinham como intenção abrigar o funcionamento da forma integral de educação, mais precisamente os CIEPs (CAVALIERE, 2002b).

No contexto da ideia de Darci Ribeiro havia traços da Educação Integral tão divulgado por Anísio Teixeira que propôs anteriormente uma escola que oferecesse uma formação que 
ultrapassasse as barreiras da sistematização do conhecimento. Múltiplas atividades curriculares, além de alimentação e cuidados básicos seriam oferecidas em dois turnos no espaço escolar excepcionalmente para o ensino infantil (CAVALIERE, 2002b; MAURÍCIO, 2004).

Também as ideias de Paulo Freire foram levadas em consideração quando surgiu a ideia de criação deste modelo de escola. Lembrando que essas instituições continham especialmente mudanças relativas ao sistema urbano que devido às adequações industriais que refletiram na população, fez com que a educação desse momento também tivesse que se enquadrar nestes aspectos (CAVALIERE, 2006)

De modo geral o tempo dos CIEPs foi marcado pela obtenção de materiais didáticos, sendo que estes foram doados para os mais carentes, além de refeições para os alunos, assistência médica e odontológica e capacitação dos professores. Contudo, a ideia da Educação Integral era fazer com que os alunos ficassem o dia inteiro na escola com a realização de atividades escolares do currículo básico e outras que possuíam características culturais e de formação humana (MAURíCIO, 2004; CAVALIERE, 2010).

\subsection{O Programa "Mais Educação" e a Educação Integral hoje: Concepções atuais da educação}

Os anos se passaram e programas com o intuito de aperfeiçoar alguns princípios da Educação Integral surgiram. Nesta direção, o programa "Mais Educação", criado oficialmente pela Portaria Interministerial no 17/2007 (BRASIL, 2007) e regulamentada pelo Decreto no 7.083/2010 (BRASIL, 2010), foi uma ideia de educadores governistas que tentavam oferecer novas ideias para as escolas e principalmente objetivando uma formação mais ampla e robusta para os alunos.

Segundo Cavaliere (2010), com a proposta de estimular a Educação Integral este programa oferecia atividades socioeducativas fora do horário normal de aula nas escolas para diversas faixas etárias enquadradas na idade escolar. Adicionalmente, a ideia de implantação foi atribuída também a alguns ministérios do governo federal e as premissas e/ou princípios foi publicada pelo MEC em seus cadernos de informações (LECLERC; MOLL, 2012). Tratava-se de uma ação intersetorial, em que todos os ministérios do governo federal dariam sua contribuição particular por meio de projetos (BRASIL, 2008).

Para Cella (2010), a sustentação ideológica do programa "Mais Educação" veio conjuntamente com as proposições da Lei de Diretrizes e Bases - LDBEN, no 9.394/96 que defendia $\mathrm{o}$ aumento crescente da jornada escolar. Com as formalidades esclarecidas coube aos estados a sequência e consolidação deste programa nas escolas, pois o governo apontava as diretrizes educacionais e disponibilizava os recursos financeiros.

Desde 2008, segundo Leclerc e Moll (2012) também existe uma parceria do MEC com estados e municípios com intuito de tornar mais sólido e fazer com que este programa cresça com o tempo. O principal desafio é conseguir torná-lo a cada dia mais impactante para formação dos alunos não só nos preceitos escolares, mas também no que diz respeito aos princípios humanos de cidadão.

No que se refere ao que representa qualquer programa para a educação atual, isto remete à qualidade do ensino e da mesma maneira ao quanto de positivo as ações governamentais por meio dos presentes ministérios são representativas para população de modo geral. Dependendo do tipo de ação até a relação escola-comunidade pode ser reforçada e auxiliar na formação educacional e humana dos alunos (CAVALIERE, 2002a; CELLA, 2010).

Em síntese, o que preocupa não é o tempo no qual as crianças e/ou jovens irão permanecer na escola e sim o quanto esse período pode representar para a formação (CAVALIERE, 2007). Enquanto que os recursos financeiros estão cada vez mais escassos é preciso saber investir com qualidade, só assim as políticas aplicadas na educação poderão proporcionar impactos positivos na vida das pessoas.

\section{CONCEPÇÕES PEDAGÓGICAS NA EDUCAÇÃO INTEGRAL: O ASSISTENCIALISMO ATRAVÉS DO “EDUCAR” VERSUS “CUIDAR”}

De acordo com Cavaliere (2007), são várias as concepções de Educação Integral no Brasil. Entre elas, podemos destacar a visão que a autora chama de "autoritária", em que a escola desenvolve a função de combate e prevenção ao crime (criança mais tempo na escola não tem tempo para prática de más condutas); a visão "democrática", que incumbe a escola de tempo integral como responsável pelo processo 
emancipatório dos alunos; a visão "multissetorial", que prega a Educação Integral realizada através de parcerias com vários setores da sociedade (a Educação deve ser oferecida também fora da escola) e, por último, a visão predominante, a "assistencialista", que vê a escola de tempo integral como um local que supre as necessidades dos menos privilegiados socialmente (a escola não é vista como local de conhecimento, mas sim de acolhimento).

Esta última visão, a "assistencialista", é o foco de nossa discussão a partir desse momento, e podemos começar pela forte influência do Banco Mundial nas políticas educacionais, ocasionando o que Libâneo (2012) chama de declínio da escola pública, pois a referida instituição financeira age de acordo com o pensamento capitalista de apenas formar mão de obra qualificada para o trabalho se esquecendo do desenvolvimento humano.

O que as políticas educacionais pós-Jomtien promovidas e mantidas pelo Banco Mundial escondem, portanto, é o que diversos pesquisadores chamaram de educação para a reestruturação capitalista, ou educação para a sociabilidade capitalista. As análises mais críticas dessas reformas educacionais são unânimes em afirmar que o pacote de reformas imposto aos países pobres gerou um verdadeiro pensamento único no campo das políticas educacionais, incluindo governos populares como o brasileiro (LIBÂNEO, 2012, p. 20-21). [Grifo do autor].

Dá para imaginar e discutir o quanto essa interferência custa caro para as pessoas que buscam se apropriar do conhecimento que é divulgado nas instituições escolares. Neste ponto, a qualidade da educação fica prejudicada e totalmente a mercê das políticas educacionais.

Ainda conforme Libâneo (2012), no que tange aos objetivos educacionais da escola básica, estes se tornam cada dia mais prejudicados, já que as instituições seguem instruções como em "cartilhas" elaboradas pelo governo, religiosamente ditadas pelos organismos internacionais. A liberdade de criar e estabelecer as próprias normas de acordo com as necessidades individuais dos alunos e coletivas da comunidade e/ou bairro fica especificamente de lado. Outros problemas podem ser vistos, como a escola que reprova, exclui os malsucedidos e, também, discrimina os pobres, fatos que levam até mesmo ao abandono escolar por parte de alguns alunos.

Outro ponto negativo é a ideia de universalização da educação, que consequentemente levam os pobres a receberem uma escola de características assistenciais e acolhedoras. De acordo com Libâneo (2012), conjuntamente com a universalização, a qualidade do ensino diminui e o governo insiste em divulgar números que apenas quantificam o acesso à escola. Assim, as instituições escolares acabam servindo mais para acolher e muito menos para educar.

Como diferentes interesses atuam sobre a educação, como por exemplo, a necessidade dos pais que trabalham e precisam deixar seus filhos na escola, as políticas educacionais acabam se aproveitando de situações como esta e focam suas atenções diretamente nos números, isto é, na quantificação dos alunos e de seus saberes, fatos que apenas mecanizam ou propriamente engessam a educação. Neste contexto, o termo básico descrito nas leis e diretrizes voltadas para a educação serve apenas para sobrevivência e pouquíssimo para o desenvolvimento humano dos estudantes (LIBÂNEO, 2012).

Acerca da formação do ser humano, é cabível dizer que suas premissas estão além da sistematização de conhecimento, pois é necessário extrapolar a reprodução automática de conteúdos. Nesta concepção, postula-se que os preceitos educacionais estimulem o intelecto e também as potencialidades individuais pertencentes a cada aluno, isto independente do ano escolar (MAURÍCIO, 2004; GOUVEIA, 2006).

Como nota final, qualquer atividade precisa estar inserida no contexto social, pois é necessário saber o que ensinar e para qual a utilidade na vida das pessoas (CAVALIERE, 2010). Percebe-se que é estritamente necessário oferecer meios que levem a uma formação de qualidade para que o tempo gasto na escola não seja em vão.

\section{1 - Educação Integral e assistencialismo: algumas discussões}

A política social está mudando para basicamente atender as necessidades reais das pessoas, isto em razão dos problemas sociais se 
tornarem tanto diferentes quanto maiores no contexto da sociedade. Nas palavras de Carvalho (2006), com a educação não é diferente, haja vista que apesar de ser um direito garantido constitucionalmente a própria tem que adaptarse diariamente às individualidades e necessidades coletivas que acontecem no interior e exterior do meio escolar. Obedecendo as carências fica mais fácil ampliar os saberes e, principalmente, dar ênfase ao desenvolvimento humano.

Ao mesmo tempo, a preocupação com a formação humana passa pelo tempo que os alunos ficam na escola e a qualidade com que este período é preenchido com as atividades. 0 que pode ser visto é que pelo motivo de o Brasil ser uma terra de desigualdades, tal fato acaba refletindo nas políticas e planos educacionais que, por sua vez, acaba tapando buracos sociais de forma insatisfatória, já que as oportunidades de formação plena e a continuidade na formação educacional são mínimas quando comparadas a outros países (BRANDÃO, 1989).

Quando a oportunidade é escassa, boa parte das políticas governamentais acaba tendo um caráter muito mais assistencialista do que qualquer outra intenção (CAVALIERE, 2002a). Sendo assim o governo aproveita-se da fragilidade social das pessoas investindo em políticas de massa que atendem a maioria da população e se esquecem, como nos lembra Libâneo (2012), de fiscalizar e adequar os planos as reais necessidades das pessoas.

$\mathrm{Na}$ questão escolar, conforme Paro (1988), um imperativo social diz que a instituição deve cumprir questões sociais e assistências, mas quando tudo fica sob a responsabilidade desta a sociedade acaba se eximindo diretamente das suas obrigações. Educar e oferecer uma formação cultural e científica é a situação educativa mais importante a ser realizada (embora muitas perspectivas ditas "científicas" perpetuem práticas de discriminações e desigualdades), pois as outras questões sociais a escola serve apenas como base de apoio para possíveis resoluções (LIBÂNEO, 2012).

Uma educação deste tipo considera o ser humano sob o ponto de vista bio-psicossocial, isto é, um misto de composição biológica material que tem suas relações e necessidades sociais (CAVALIERE, 2010).

Em definição específica, para Maurício (2002) e Cavaliere (2010) a educação em tempo integral se atrela à extensão do tempo na escola, o qual é preenchido com atividades que possuem aspectos socioeducativos, isso nos tempos atuais. Em outras épocas, como por exemplo, na década de 1950, período efetivo da criação das primeiras escolas de tempo integral, neste momento o intuito era renovar a educação e as diretrizes além de socializar e democratizar o jovem.

De certa forma, conforme Maurício (2006), pode-se considerar este tipo de educação como especial, já que uma atenção diferente é dada ao tempo em que aluno está na escola. Isso não quer dizer que este sistema seja perfeito, haja vista que a extensão do horário das atividades escolares não garante precisamente qualidade de ensino, tampouco de aprendizado. Essa extensão indica presumidamente certo assistencialismo por parte da instituição escolar, o qual é amplamente anunciado pelas políticas governamentais.

\section{2 - Educação Integral, currículo e organização escolar}

Os modelos de Educação Integral atuais consideram a aplicação de atividades socioeducativas essencialmente no contraturno do horário tradicional escolar. Gonçalves (2006) destaca que este modelo deve também levar em conta parâmetros como tempo, que é indicado pelo aumento da jornada escolar, além do espaço, que sobretudo é observado no âmbito escolar mais precisamente nas salas, pátio etc.

A estimulação, a formação e o desenvolvimento humano podem ser feitos tanto nas disciplinas e/ou atividades formais como nas que excedem o horário formal de aula nas escolas, pois o tempo na escola deve ser bem aproveitado (CAVALIERE, 2007). Dento deste contexto, inclui-se a Educação Integral e mais precisamente a escola em tempo integral, as quais oferecem atividades extracurriculares (GOUVEIA, 2006).

No que remete as atividades, podemos citar alguns exemplos, como a música, pois é uma proposta interessante e oferece, excepcionalmente, a cultura aos discentes. Este método é indicado inclusive pela atual LDBEN com o intuito de formar cidadãos críticos e atuantes. No entanto, são necessários materiais suficientes e profissionais capacitados para que haja aproveitamento máximo (PENNA, 2011).

Entre outras práticas educativas, Gouveia (2006) cita a prática esportiva como outro exemplo, já que o esporte quando desprendido dos aspectos de rendimento se torna mais 
educacional. Inúmeros projetos de cunho formativo oferecem modalidades esportivas e na educação integral não é diferente, porque também é possível ensinar valores que podem ser levados para vida do cidadão, como por exemplo, respeito, ética e cooperação entre as pessoas.

A informática também tem sido aplicada da mesma forma, posto que o acesso e uso da tecnologia se tornam mais importantes a cada dia, tanto para participação na vida pública como para o desenvolvimento pessoal, isto sem deixar de lado o caráter pedagógico, o qual é essencial para qualquer formação(GOUVEIA, 2006).

\section{CONSIDERAÇÕES FINAIS}

Estimular o desenvolvimento humano requer atenção e um ambiente escolar sem dualismos, como os das escolas brasileiras, que fornece conhecimento para os ricos e acolhimento social para os pobres (LIBÂNEO, 2012). O estímulo vai além disso e de acordo com Cavaliere (2002a) aumentar as atividades ou o tempo das mesmas como acontece na Educação Integral, sem pensar em mudanças pedagógicas, não é suficiente. Devem ser reconhecidas as individualidades e as necessidades humanas e fazer com que as pessoas se desenvolvam a partir disso. A educação em tempo integral é um modelo que vem sendo adotado há muitos anos por várias instituições, sendo estas de característica pública ou privada. Neste modelo, conforme Kerstenetzky (2006) e Gonçalves (2006) - aluno passa boa parte do dia realizando atividades na escola, as quais tem aspecto estritamente educativo visando a formação do cidadão.

O termo educação integral diz tudo, ou seja, vai além do tempo escolar e as atividades extrapolam os conteúdos tradicionais, as quais devem especialmente nutrir novas aprendizagens além de ampliar práticas sociais e culturais ao longo da jornada escolar (LECLERC; MOLL, 2012). Programas como estes já estão consolidados através de ações governamentais e participação da iniciativa privada, o que é necessário, portanto, é não perder o foco e não deixar de oferecer atividades que contemplem uma melhora na qualidade educacional brasileira (CAVALIERE, 2010).

Ultrapassar a sistematização e propriamente abster-se dela é algo que incita o ser humano a ser dono de seu pensamento. Assim, a reprodução automática de conteúdo fica de lado e desenvolver-se enquanto homem é uma questão de tempo. Em referência à Educação e o que ela pode propiciar, não basta saber fazer, é preciso entender o motivo para o aprendizado e principalmente para o desenvolvimento humano.

A educação integral, como nos lembra Cavaliere (2007), tem como intuito não só estender as horas de atividades escolares, mas também oferecer métodos que impliquem na construção de pensamento pelo próprio aluno. Expectativas são muitas com relação a este modelo, no entanto, a edificação dele passa pela relevância social e vai precisamente até o quanto pode estimular devidamente o ser humano de forma completa.

\section{REFERÊNCIAS}

AZEVEDO, N. C. S. Programa Cidadescola no 1을 ano do Ensino Fundamental em uma escola de Presidente Prudente: entre a ludicidade e a sala de aula. 2012. 213 f. Dissertação (Mestrado em Educação) - Universidade Estadual Paulista UNESP, Presidente Prudente, 2012.

BRANDÃO, Z. A escola de 10 grau em tempo integral: as lições da prática. Educação e Sociedade, n. 32, 1989, p. 116-129.

BRASIL. Ministério da Educação. Portaria Normativa Interministerial no 17 de 24 de Abril de 2007. Institui o Programa "Mais Educação", que visa fomentar a educação integral de crianças, adolescentes e jovens, por meio do apoio a atividades socioeducativas no contraturno escolar. Brasília, 2007.

BRASIL. Ministério da Educação. Secretaria de Educação Continuada, Alfabetização e Diversidade. Diretoria de Educação Integral, Direitos Humanos e Cidadania. Programa Mais Educação. Passo a Passo. Brasília, 2008.

BRASIL. Presidência da República. Casa Civil. Subchefia para Assuntos Jurídicos. Decreto n7.083, de 27 de janeiro de 2010. Dispõe sobre o Programa "Mais Educação". Brasilia, 2010.

CARVALHO, M. C. B. O lugar da Educação Integral na política social. Cadernos Cenpec, n. 2, 2006, p. $7-11$. 
CAVALIERE, A. M. Educação integral: uma nova identidade para a escola brasileira? Educação \& Sociedade, Campinas, v. 23 , n. 81 , p. 247-270, dez. 2002a. https://doi.org/10.1590/S010173302002008100013

CAVALIERE, A. M. V. (Orgs). Educação Brasileira e(m) Tempo Integral. Petrópolis: Vozes, 2002b. p. 133-146.

- Tempo de escola e qualidade na educação pública. Educação \& Sociedade, Campinas, v. 28, n. 100, esp, p. 1015-1035, out. 2007.

Escolas de tempo integral versus alunos em tempo integral. Em aberto, Brasília, v.22, n. 80, p. $51-63$, Abr. 2009.

Anísio Teixeira e a educação integral. Paidéia, v. 20, n. 46, p. 249-259, mai./ago. 2010.

COELHO, L. M. C. C. História(s) da educação integral. Em Aberto, Brasília, v. 22, n. 80, p. 8396, abr. 2009.

CELLA, R. EDUCAÇÃO INTEGRAL NO BRASIL: HISTÓRIA, DESAFIOS E PERSPECTIVAS. 2010. $94 \mathrm{f}$. Dissertação (Mestrado em Educação) - Faculdade de Educação, da Universidade de Passo Fundo, Passo Fundo, 2010.

GONÇALVES, A. S. Reflexões sobre Educação Integral e escola de tempo integral. Cadernos Cenpec, n.2, 2006, p. 129-135.

GOUVEIA, M. J. A. Educação Integral com a infância e a juventude. Cadernos Cenpec, n.2, 2006, p. 77-85.

KASSICK, C. N. Pedagogia libertária na história da educação brasileira. Revista HISTDBR, Campinas, n. 32, p. 136-149, dez. 2008.

KERSTENETZKY, C. L. Escola em tempo integral já: quando quantidade é qualidade. Ciência Hoje, v. 39 , n. 231, p. 18-23, out. 2006.

LECLERC, G. F. E.; MOLL, J. Programa Mais Educação: avanços e desafios para uma estratégia indutora da Educação Integral e em tempo integral. Educar em Revista, Curitiba, Brasil, n. 45, p. 91-110, jul./set. 2012.
LIBÂNEO, J. C. O dualismo perverso da escola pública brasileira: escola do conhecimento para os ricos, escola do acolhimento social para os pobres. Educação e Pesquisa, São Paulo, v. 38, n. 1, p. 13-28, 2012. https://doi.org/10.1590/S1517$\underline{97022011005000001}$

MAURíCIO, L. V. Permanência do horário integral nas escolas públicas do Rio de Janeiro: no campo e na produção escrita. In: COELHO, L. M. C.; CAVALIERE, A. M. V. (Orgs). Educação Brasileira e(m) Tempo Integral. Petrópolis: Vozes, 2002. p. 112-132.

- Literatura e representações da escola pública de horário integral. Revista Brasileira de Educação, n. 27, p. 40-56, set/dez. 2004.

- O que se diz sobre a escola pública de horário integral. Cadernos Cenpec, n. 2, p. 57-67, 2006.

MOLL, J. Caminhos da Educação Integral no Brasil. Direito a outros tempos e espaços educativos. Porto Alegre: Penso, 2012.

OLIVEIRA, C. A. CIEP: modelos subjacentes de uma escola que está fazendo escola. 1991. Dissertação (Mestrado) - Faculdade de Educação, Universidade Federal do Rio de Janeiro, Rio de Janeiro, 1991.

PARO, V. Viabilidade da escola pública em tempo integral. Educação e Sociedade, n. 29, p. 86-99, 1988.

PENNA, M. Educação musical e educação integral: a música no Programa Mais Educação. Revista da ABEM, Londrina, v.19, n. 25, Jan./ Jun. 2011, p. 141-152.

Recebido para publicação em: 19/04/2016

Revisado em: 22/04/2016

Aceito em: 25/04/2016 